\title{
Doctor-Patient Relationship in General Medicine Has a Diagnostic Meaning
}

\section{Jose Luis Turabian}

Specialist in Family and Community Medicine, Health Center Santa Maria de Benquerencia, Regional Health Service of Castilla la Mancha (SESCAM), Toledo, Spain.

E-mail Id: jturabianf@hotmail.com

\section{ABSTRACT}

The doctor-patient relationship is not only based on the contributions of the doctor, or only based on the patient's, but is formed through the interaction of the contributions of both. But, the relationship that the patient tends to create with the doctor has a latent meaning concerning the reason for that patient's consultation. That is, it has a diagnostic meaning. In this way, the general practitioner (GP) can search for information about what seems to be the cause of the patient's problem, in addition to other sources, based on the type of relationship that the patient establishes with him. In this way, the patient's interpersonal relationship can be reproduced in the consultation, between patient and doctor. So, the type of doctor-patient relationship, which tends to be created by the patient, partially points out the content of the latent material of reason for the consultation; it partially points to the diagnosis. Thus, the following types of patient's relationship with the doctor in the clinical encounter can be observed: 1) "Dependent relationship"; 2) "Manipulative relationship"; 3) "Demanding or angry relationship"; 4) "Victim relationship"; 5) "Distant relationship"; 6) "Relationship with excessive familiarity or closeness"; 7) "Submissive relationship"; 8) "Masochistic relationship"; 9) "Sadistic relationship": 10) "Hyperactive or impatient relationship"; 11) "Indifferent relationship"; 12) "Narcissistic relationship"; Etc. If the GP passes through the doctor-patient relationship as blind to its existence, without realizing it, using only a medical model that explicitly directs its attention away from this doctor-patient relationship, it will lose many possibilities to understand the consultation, among them, an important one that is not mentioned: the possibility of orienting the diagnosis in general medicine.

Keywords: General Practice; Framework; Diagnostic techniques; Sanitary Attention; Physician-patient communication, Physician-Patient Relations; Symptom assessment; Biopsychosocial

\section{Introduction}

Although the doctor-patient relationship can not be expressed in numbers or reflected in health statistics, there is overwhelming evidence that it continues to determine to a large extent the effectiveness of individual medical care. Its usefulness has been reported to obtain better therapeutic results, its value in itself as a therapy, its value to obtain better data by obtaining more biopsychosocial information, more patient satisfaction, etc. (1-8). 
On the other hand, due to the predominant biologicist approach in medicine, in the general medicine practice there is a priority focus in the collection and description of the symptoms and signs of "biological" stock and priority is given to technological tests (secondary data versus the patient's primary data).

Since at least $30-50 \%$ of all outpatients who visit the general practitioner present discomfort that does not correspond to the tables of the WHO International Classification (9-12), the deficiencies that result from this produce inaccuracies are the collection of clinical data, increased expense, unnecessary discomfort to the patient, and increased interpretation errors whose consequences can be unpredictable (overdiagnosis, overtreatment, iatrogenesis, etc.). And these deficiencies and inaccuracies are, even greater for psychological and social data.

It can, then, be said that there is an insufficiency in the strict biomedical models to conceptualize and manage the problems of medical care. If in real day-to-day practice, it becomes very difficult to abandon the reductionist biological approach (which, on the other hand, has brought so many achievements in the last 50 years), at least, it is necessary to incorporate a broader framework, which can allow understanding and attending to the patient in addition to the disease.

For this, one way is to learn to know and handle the "relational dimension", where subjective experiences are. And a natural "door" in the consultation of general medicine, to know that dimension, is the doctor-patient relationship.
Of course, the doctor-patient relationship is a subject that has been the object of numerous analyzes, although in general in a simplistic manner. The doctor-patient relationship is not the result or it does not take the form only based on the contributions of the doctor, or only based on the patient's, but is formed through the interaction of the contributions of both $(2,13)$.

However, a forgotten aspect, and not mentioned at all in recent analyzes (since Freud until now!) (14), is its value for diagnosis: The relationship means something; indicates something (15).

In this context, this article aims to reflect on the value that the doctor-patient relationship has in diagnosing the health problem in general medicine.

\section{Discussion}

The relationship that the patient tends to create with the doctor has a latent meaning with regard to the reason for the consultation of that patient. That is, it has a diagnostic meaning. In this way, the doctor can search for information about what seems to be the cause of the patient's problem, in addition to other sources, in the doctor-patient relationship.

The type of doctor-patient relationship, which tends to be created by the patient, partially points out the content of the latent material of reason for the consultation; it partially points to the diagnosis. Thus, the following types of patient's relationships with the doctor in the clinical encounter can be observed $(16,17)$. 
Table: 1 Some types of patient's relationship with the doctor in the clinical encounter that can be observed

\begin{tabular}{|l|l|}
\hline & Types of patient's relationship with the doctor \\
\hline 1 & Dependent relationship \\
\hline 2 & Manipulative relationship \\
\hline 3 & Demanding or angry relationship \\
\hline 4 & Victim relationship \\
\hline 5 & Distant relationship \\
\hline 6 & Relationship with excessive familiarity or closeness \\
\hline 7 & Submissive relationship \\
\hline 8 & Masochistic relationship \\
\hline 9 & Sadistic relationship \\
\hline 10 & Hyperactive or impatient relationship \\
\hline 11 & Indifferent relationship \\
\hline 12 & Narcissistic relationship \\
\hline
\end{tabular}

Dependent relationship" (fear of abandonment and struggle for power and control of the behavior of others, for example in the family, as of the child over the parents, and which usually occurs, for example, in patients with irritable bowel syndrome; These patients tend to suffer disorders related to anxiety and depression; there may be a coldness in the relationship, as well as in the narration of the story of problems and the use of concrete thought, with few possibilities to develop hypotheses about the causes of their difficulties or problems. They can present worsening of somatic symptoms when the doctor does not keep repeated appointments with patient.
Patient can react with symptoms of digestive, dermatological disease, headaches, dizziness, dyspepsia, asthma, etc., in the proximity of "feeling abandoned", since by means of the disease he can subdue his environment and at the same time punish nearby actors -family, doctor, etc.- by having the all turn around him).

Manipulative relationship" (in patients with hysterical personality, drug abuse, including repeated requests for benzodiazepines. They project blame, becoming they the injured; they have a high capacity for seduction; they have the gift of liking people and are able to support and praise others; they do not talk 
about the important issue, it is avoided and it is made as if it did not exist).

Manipulative relationship" (in patients with hysterical personality, drug abuse, including repeated requests for benzodiazepines. They project blame, becoming they the injured; they have a high capacity for seduction; they have the gift of liking people and are able to support and praise others; they do not talk about the important issue, it is avoided and it is made as if it did not exist).

Demanding or angry relationship" (history of abuse by other people or situations, or repeated failures; patient feels hurt by something, or because of he is not understood for other people, or that other people not wished to understand him. It is a secondary reaction to different emotions such as frustration, the loss of a loved one, anxiety or fear, or feeling of being underestimated: "Nothing ever works", unrealistic expectations).

Victim relationship" (in adaptive disorders such as depression and anxiety; patient can feign pain and seeks to give sorrow).

Distant relationship" (which puts barriers to the relationship; something that has happened to him in the past, perhaps due to failed relationships in his most important links, such as a bad relationship with his parents, his brothers or his people in the most intimate context, or with other health professionals, and does not want to be damaged again).

Relationship with excessive familiarity or closeness" (in inhibited depression - the patient who always finishes the visit by kissing the GP, although he tries to avoid it, while she begins to cry- for example; there is a search for "human warmth" that can signal the lack or hostility over father figures).

Submissive relationship" (a past full of abuse, lack of assertiveness, social phobia, etc.). The patient presents frequently "discomfort", asthenia other symptoms of stress.

Masochistic relationship" (feeling of guilt and expiation of guilt; unconscious need to be punished as a result of a damaged self-esteem in which the person feels that it is worthless, that he is bad and deserves punishment; The patient try to avoid a deeper suffering like abandonment or lack of control).

Hyperactive or impatient relationship" (patients who are always under the pressure of time, who demand that their appointment is not delayed, that is prescribed to him so that they do not need to return to consultation, etc. It mean a risk factor for hypertension and ischemic heart disease: angina pectoris and myocardial infarction).

Indifferent relationship" (the patient expresses his problems with coldness, indifference and blames all his psychological problems to the organic disease - for example, a patient with rheumatoid arthritis that blames the depressive symptoms of that disease - although there are other important conflicts not resolved at the relational level).

Narcissistic relationship" (in it the patient is proud of himself of his position, of his economic or cultural level, of what he has achieved, with his effort in front of others and his challenges and difficulties, he frequently consults private doctors and boasts of their costs; He can explain their high level of life, can express anger about those who hindered their achievements, this behavior often refer to previous relational conflicts with parents 
or siblings, the patient to repress and therefore have unconscious their aggressiveness towards these actors meaningful; He feels guilty of his desires to destroy them and in his fantasy, a way to carry out these desires, was to overcome them through intellectual and economic progress and boast before them of the achievements, but also brings the punishment of organic symptoms such as headache, dizziness, dyspepsia, etc.). Etc.

The disease may threaten the patient's sense of connection with others or with the world, and may be the result, at least in part, of the alteration of their relationships and connections. This mode of interpersonal relationship can be reproduced in the consultation, between patient and doctor. The disease can interfere with patient safety and challenge their sense of control over their fate; this causes changes in their interpersonal relationships, and these relational interferences are also expressed in the patient's relationship with the doctor, unconsciously signalling the psychosocial factors of health problems. Pain, loss of function and other types of problems diminish the possibilities of contact by increasing the feeling of isolation in daily life, and this situation is also reflected in the relationship that tends to create with your GP that shows these feelings (be isolated, desperate, into a tunnel with no exit, disconnected, oppressed, etc.).

Of course, the diagnostic value of the doctorpatient relationship can be shown in only one visit, but it is more usual to require several or many successive visits. Likewise, its value in illuminating the diagnosis can be presented in phases or moments over time, in which the interviews (in which the diagnostic process is carried out: the translation of a material manifested by the patient, to another more latent complete and clear) seem to stoping or may appear conflicts in the doctor-patient relationship over time, in continued care, circumstances that represent in themselves part of those latent contents; that is, part of the diagnosis.

Obviously, the doctor-patient relationship is a two-way road, and can be influenced from the doctor's side by the mechanisms of countertransference, not listening to our patients which negatively impacts rapport, not providing empathy or substituting sympathy, o projective identification (patients can project intolerable and negative feelings onto us and coerce us into identifying with what has been projected, allowing them to indirectly take control of our emotions). Our patients could give rise to these dynamics by the doctor. Therefore, GP must be careful not to negatively affect the doctor-patient relationship (18).

However, it is important to remember that in any doctor-patient relationship an unconscious transferentialcountertransferential process is established that influences the management that the doctor gives to his patients. If the doctor does not find organic cause to the symptoms of his patient, he can react, among other things with disinterest, annoyance or insecurity, feelings that are feasible to generate unconscious attitudes of rejection with the consequent difficulty to engage in an enlightening dialogue about the problematic biopsychosocial of the patient (17).

That is, by modifying doctor-patient relationship, the latent meaning of this relationship is masked as the patient creates it, and as a result it loses its diagnostic value 
(independently of the rest of the negative effects of poor communication that results in a worse perception by the patient of his state of health, more referrals, etc.). (19-22).

\section{Conclusion}

It makes the GP to lose many possibilities to understand the query, and among them, an important one that is not usually mentioned: losing the possibilities of guiding the diagnosis in general medicine, because the relationship that the patient tends to create with his GP can allow to that part of the patient' latent material which is not manifest in the reason for consultation is understood by doctor. That is, to approach the biopsychosocial diagnosis of the patient.

Figure1 Doctor-Patient relationship in general medicine has a diagnostic meaning

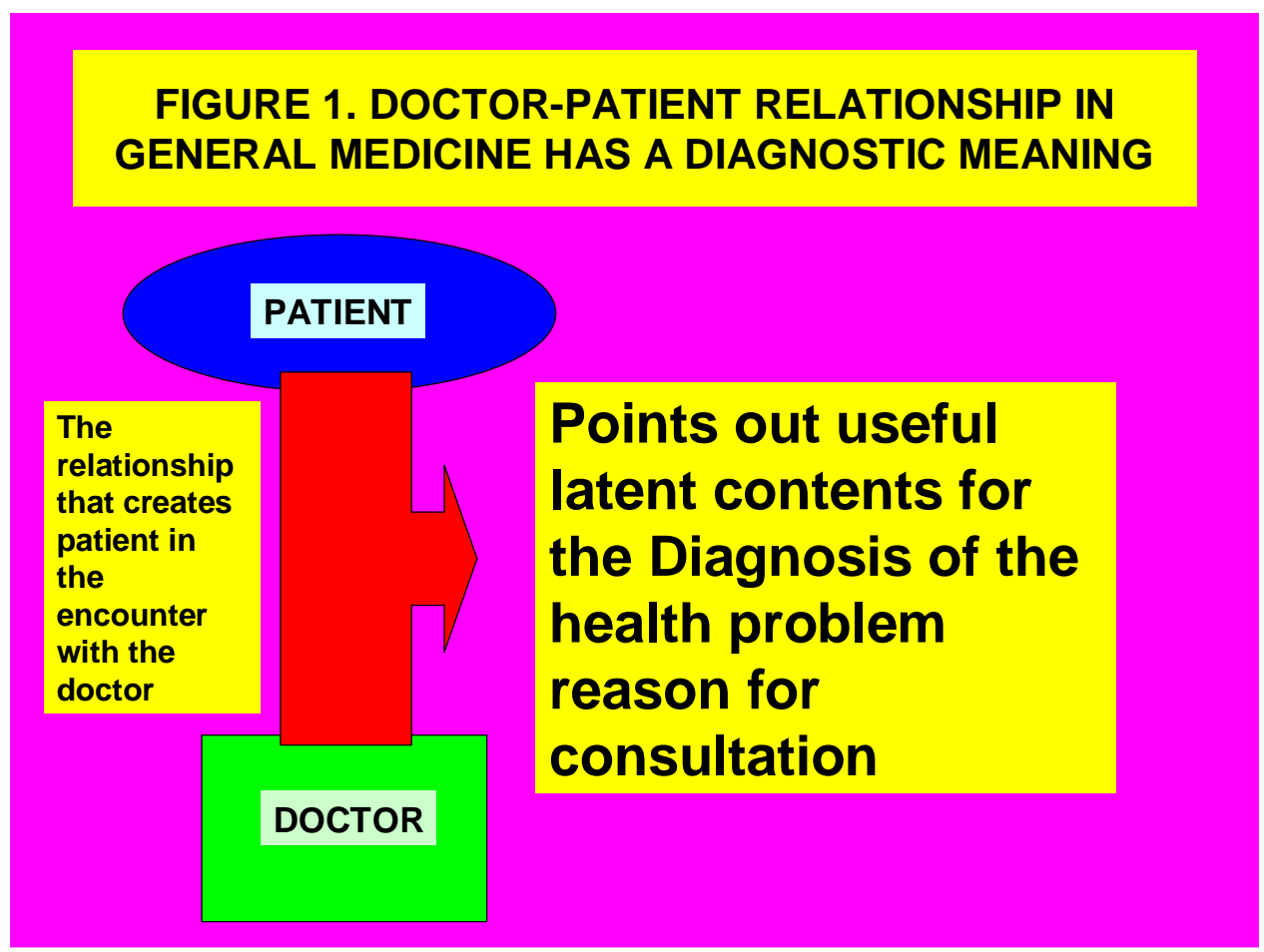

\section{References}

1. Cagli V (2008) [The clinical method and its evolution]. [Article in Italian]. Med Secoli; 20(1):19-42. https://www.ncbi.nlm.nih.gov/pubm ed/19569410

2. Turabian JL (2019) Doctor-Patient Relationships: A Puzzle of Fragmented Knowledge. J Family Med
Prim Care Open Access 3: 128. DOI: 10.29011/JFOA-128/100028. In Press.

https://www.gavinpublishers.com/jo urnals/artical in press/familymedicine-and-primary-care-openaccess.html

3. Ha JF, Longnecker N (2010) DoctorPatient Communication: A Review. Ochsner J; 10(1): 38-43. 
https://www.ncbi.nlm.nih.gov/pmc/a rticles/PMC3096184/

4. White P (2005) Biopsychosocial medicine. An integrated approach to understanding illness. New York: Oxford University Press.

5. Polinski JM, Kesselheim AS, Frolkis JP, Wescott P, Allen-Coleman C, Fischer MA (2014) A matter of trust: patient barriers to primary medication adherence. Health Educ Res; 29 (5): 755-63.

http://her.oxfordjournals.org/conten t/29/5/755.abstract.html?etoc

6. Laws MB, Beach MC, Lee Y, Rogers WH, Saha S, Korthius PT, et al. (2013) Provider-patient Adherence Dialogue in HIV Care: Results of a Multisite Study. AIDS Behav; 17(1): 148-59. https://doi.org/10.1007/s10461012-0143-z

7. Turabian JL (2018) Doctor-Patient Relationship as Dancing a Dance. Journal of Family Medicine; 1(2): 1-6. https://openaccesspub.org/ifm/articl e/912

8. Rajaram U (2012) The patient-doctor relationship. Indian J Med Ethics; 9(3): 156-7. https://www.ncbi.nlm.nih.gov/pubm ed/22864068

9. Philip Hopkins (Editor) (1972) Patient-Centred Medicine. Based on the First International Conference of Balint Society in Gran Britain on "The Doctor, His Patient and the Illness", held on 23rd-25rd March, 1972 al the Royal College of Physicians, London. London: Regional Doctor Publications Limited.

10. Turabian JL (1995) [Family and Community Medicine notebooks. An Introduction to the Principles of
Family Medicine]. Madrid: Díaz de Santos.

http://www.amazon.co.uk/Cuaderno s-medicina-familia-ycomunitaria/dp/8479781920

11. Turabian JL (2018) Presentation and Approach of Disorganized Disease in Family Medicine. J Fam Med Forecast; 1(1): 1001. https://scienceforecastoa.com/Articl es/JFM-V1-E1-1001.pdf

12. Turabian JL (2018) Hypothesis for a Theory about the Disorganized Health Problems in General Medicine: The Hidden Face of the Moon. Epidemol Int J; 2(3): 000114. https://medwinpublishers.com/EIJ/E Ij16000115.pdf

13. Turabián JL, Pérez Franco B (2015) [Observations, insights and anecdotes from the perspective of the physician, for a theory of the natural history of interpersonal continuity. The colors of time]. [Article in Spanish]. Rev Clin Med Fam; 8(2). http://www.revclinmedfam.com/arti culo.php?art $=412$

14. Freud S (1966) Interpretation of Dreams. London: Sigmund Freud Copyright, Ltd.

15. Turabian JL (2019) Interpretation of the Reasons for Consultation: Manifest and Latent Content. the Initiation of the Diagnostic Process in General Medicine. Archives of Community and Family Medicine; 2(1).

https://www.sryahwapublications.co $\underline{m}$ /archives-of-community-andfamily-medicine/pdf/v2-i1/1.pdf

16. González Menéndez R (1979) Psicología para médicos generales. 
Ciudad de La Habana, Cuba: Editorial Científico-Técnica.

17. Sánchez Medina A (2006) [The disorders of the thought and the psychosomatic diseases]. [Article in Spanish]. Revista MEDICINA; 28(4) (75): 161-79.

18. Joshi KG (2017) 'Difficult' patients: How to improve rapport. Curr Psychiatr; 16(8): 49. https://mdedgefiles-live.s3.us-east-

2.amazonaws.com/files/s3fspublic/Document/July2017/cp01608049.pdf

19. Frequent attenders and difficult patients management (2007) Essential competences of the family doctor. Chapter 3- Clinical interview: special and / or complicated situations. [Homepage in Internet]. [Article in Spanish]. El Médico. http://2011.elmedicointeractivo.com /formacion acre $2007 / \mathrm{modul}$ os/mod ulo9/csc2.php

20. Ahumada JL (1994) What is a clinical fact? Clinical psychoanalysis as inductive method. Int J Psychoanal; 75(Pt 5-6): 949-62. https://www.ncbi.nlm.nih.gov/pubm ed/7713672

21. Cooper SH (2010) An elusive aspect of the analyst's relationship to transference. Psychoanal Q; 79(2): 349-80.

https://www.ncbi.nlm.nih.gov/pubm ed/20496836

22. Colman W (2009) Theory as metaphor: clinical knowledge and its communication. J Anal Psychol; 54(2): 199-215.

https://www.ncbi.nlm.nih.gov/pubm ed/19344314
How to cite this Article: Jose Luis Turabian, Doctor-

Patient Relationship in General Medicine Has a Diagnostic Meaning

Int. Res. Med. Health Sci., 2019; (2-5): 20-27

Source of Support: Nil, Conflict of Interest: None declared.

Received: 5-9-2019; Revision: 8-10-2019;

Accepted: 20-10-2019; Published: 5-11-2019 